\title{
Festa literária de Santa Maria em casa: atuação no contexto de pandemia
}

\section{Santa Maria literary festival at home: performance in the context of pandemic}

\section{Fiesta literaria de Santa María en casa: actuación en el contexto de pandemia}

\author{
iD) Camila Steinhorst \\ Universidade Federal de Santa Maria \\ iD (9) Aylon de Oliveira Dutra \\ Universidade Federal de Santa Maria \\ iD (9) Raquel Trentin Oliveira \\ Universidade Federal de Santa Maria
}

Resumo: Neste trabalho, refletimos sobre o potencial que as festas literárias podem assumir na mediação cultural e na formação de leitores, com base no contexto específico da Festa Literária de Santa Maria (FLISM), projeto de extensão da Universidade Federal de Santa Maria, RS, que reinventou seu formato no ano de 2020 como ação para enfrentamento da pandemia de Covid-19. Realizamos uma pesquisa descritiva, de natureza quantitativa e qualitativa. Para a análise quantitativa, embasamo-nos no relatório de prestação de contas da segunda edição do evento e em dados dis- 
ponibilizados pelas plataformas digitais da terceira edição. Para a qualitativa, utilizamos um formulário online para refletirmos acerca da recepção dos participantes, apoiados em Candido (2004), Zilberman (2013), Cosson (2016), entre outros. Concluímos que o evento pode colaborar com o letramento literário de seus participantes e promover bem-estar. Assim, é fundamental garantirmos a permanência de festas literárias para democratizar e significar a literatura em espaços não institucionais.

Palavras-chave: Extensão universitária. Festa Literária. Mediação Cultural em contexto de pandemia. Formação de Leitores.

Abstract: In this work, we reflect on the potential that literary festivals can assume in cultural mediation and in the formation of readers, based on the specific context of the Literary Festival of Santa Maria (FLISM), extension project of the Federal University of Santa Maria, RS, which reinvented its format in 2020 as an action to combat the Covid-19 pandemic. We conducted a descriptive, quantitative and qualitative research. For the quantitative analysis, we rely on the accountability report of the second edition of the event and on data made available by the digital platforms of the third edition. For the qualitative, we used an online form to reflect on the reception of the participants, supported by Candido (2004), Zilberman (2013), Cosson (2016), among others. We conclude that the event can collaborate with the literary analysis of its participants and promote well-being. Thus, it is essential to ensure the permanence of literary festivals to democratize and signify literature in non-institutional spaces.

Keywords: University extension. Literary Festival. Cultural Mediation in the context of pandemic. Formation of Readers.

Resumen: En este trabajo, reflexionamos sobre el potencial que las fiestas literarias pueden asumir en la mediación cultural y en la for- 
mación de lectores, sobre la base del contexto específico de la Fiesta Literaria de Santa María (FLISM), proyecto de extensión de la Universidad Federal de Santa María, RS, que reinventó su formato en el año 2020 como acción para hacer frente a la pandemia de Covid-19. Realizamos una investigación descriptiva, de naturaleza cuantitativa y cualitativa. Para el análisis cuantitativo, nos basamos en el informe de rendición de cuentas de la segunda edición del evento y en datos disponibles por las plataformas digitales de la tercera edición. Para la calidad, utilizamos un formulario online para reflexionar sobre la recepción de los participantes, apoyados en Candido (2004), Zilberman (2013), Cosson (2016), entre otros. Concluimos que el evento puede colaborar con el entrenamiento literario de sus participantes y promover el bienestar. Así, es fundamental garantizar la permanencia de fiestas literarias para democratizar y significar la literatura en espacios no institucionales.

Palabras clave: Extensión universitaria. Fiesta Literaria. Mediación Cultural en contexto de pandemia. Formación de Lectores.

Data de submissão: 17/11/2020

Data de aprovação: 16/12/2020 
Festa literária de Santa Maria em casa: atuação no contexto de pandemia Camila Steinhorst • Aylon de Oliveira Dutra, et al...

\section{Introdução}

De acordo com os resultados da pesquisa Retratos da leitura no Brasil (2016), realizada pelo Instituto Pró-livro, só 56\% da população brasileira pode ser considerada leitora, e, segundo os seus critérios, o que caracteriza uma pessoa como tal é ter lido algum livro (ou parte dele) nos últimos três meses. O que esse dado nos revela é a necessidade de iniciativas voltadas para a formação e conservação de leitores, visto que a leitura, como bem já dizia Antonio Candido (2004), em seu famoso ensaio, é um direito, e um direito garantido por lei. Sancionada em 12 de julho de 2018, a Lei No 13.696, também conhecida como Lei Castilho, institui “a universalização do direito ao acesso ao livro, à leitura, à escrita, à literatura e às bibliotecas" (BRASIL, 2018). Enquanto os planos municipais e estaduais de regulamentação da Lei Castilho são instituídos, cabe aos professores de literatura, aos mediadores de leitura, aos bibliotecários, e aos demais profissionais relacionados ao livro, promoverem práticas diversas que busquem atingir a população como um todo.

Assim, o incentivo à formação de leitores não deve se restringir aos espaços escolares ou institucionais, até porque, mesmo nesses lugares, a presença da leitura literária tem sido cada vez menor. Segundo Zilberman (2009, p. 19), tendo surgido em épocas próximas, "a escola e a leitura se aproximam, e a crise de uma também é a crise de outra". Tal problemática tem levantado hipóteses que relacionam a restrição das atividades de leitura literária nas instituições de ensino ao desaparecimento da literatura. Em outras palavras, se, a partir de aulas sobre periodização, ou daquelas que se ocupam apenas de fragmentos de obras em livros didáticos, identificamos indícios do estreitamento do espaço da literatura na escola, então poderíamos considerar o seu fim? 
Festa literária de Santa Maria em casa: atuação no contexto de pandemia Camila Steinhorst • Aylon de Oliveira Dutra, et al...

Cosson (2019, p. 15) assegura que “o que está em processo de obsolescência são as formas que a tradição conhece e valoriza como literárias", citando a popularidade de uma série de manifestações artísticas surgidas nas últimas décadas, em decorrência das mudanças de ordem social. Manifestações como a indústria musical e cinematográfica, as histórias em quadrinhos, a literatura eletrônica, a televisão, as redes de streaming, os jogos de RPG (Role-playing game), e a Internet, permitem que leitores de determinadas obras, autores ou gêneros passem a se identificar como grupo, discutir em fóruns, escrever fanfics, assistir resenhas de booktubers, e a ganhar a atenção do mercado editorial.

Muitas vezes, mesmo os alunos que são leitores, ou que consomem conteúdo digital sobre livros, não sentem prazer nas leituras que fazem por obrigação na escola, assim como existem adultos que lembram com pesar de clássicos que foram forçados a ler. Dessa forma, devemos refletir sobre maneiras de criar espaços de discussão literária que prezem pela liberdade e que estimulem leitores e não leitores a conhecerem diferentes obras e autores. Segundo Petit (2013, p. 37), tudo que podem fazer os mediadores de leitura "é multiplicar as ocasiões de encontros, de descobertas" e "criar espaços de liberdade onde os leitores possam traçar caminhos desconhecidos e onde terão disponibilidade para discutir com eles sobre essas leituras, se assim as desejarem".

Nesse sentido, influenciados pelas transformações que a sociedade passou quanto à forma de se relacionar com a leitura, surgem eventos voltados para a literatura e que abrangem um público diverso, não se restringindo ao universitário, sendo os mais populares, no caso brasileiro, a Bienal do Livro (São Paulo - SP), a FLIP (Festa Literária de Paraty - SP), a Fliaraxá (Festival Literário de Araxá) e a Jornada Nacional da Literatura (Passo Fundo - RS). 
Festa literária de Santa Maria em casa: atuação no contexto de pandemia Camila Steinhorst • Aylon de Oliveira Dutra, et al...

Popularizadas no século XXI, no Brasil, as festas literárias são espaços de discussão e encontro entre leitores e autores. Influenciados pela popularidade atingida pela FLIP, cuja primeira edição ocorreu em 2003, hoje podemos encontrar um grande número de eventos desse tipo em todas as regiões do país. Apesar dessa iniciativa favorável de organizadores pertencentes a diferentes camadas da sociedade (poder municipal, organização de bibliotecários, mercado editorial, entre outros), o contexto gaúcho sinaliza uma preocupação. As Jornadas de Passo Fundo, que tornaram a cidade reconhecida mundialmente, não têm acontecido por falta de investimento público. Ao comentar o sucesso das Jornadas e as consequências de sua realização para a cidade, Rösing (2009, p. 211) lembra que o número de livrarias aumentou surpreendentemente para o tamanho do município, no norte do Rio Grande do Sul, e a média de livros lidos por habitante se tornou maior, inclusive, que a média da capital, Porto Alegre - resultado de três décadas de promoção da leitura na cidade.

Nesse contexto de grande perda para o estado, mas também de efervescência de festas literárias pelo país, surge a Festa Literária de Santa Maria. A Festa Literária de Santa Maria (FLISM) é um projeto de extensão da Universidade Federal de Santa Maria (UFSM), que nasceu da idealização de três professores da instituição, dos Cursos de Letras e de Música, respectivamente, Raquel Trentin Oliveira, Enéias Tavares e Gérson Werlang. Segundo informações do portal de projetos da UFSM'1', a FLISM objetiva aproximar a Universidade da comunidade em geral, especialmente a de Santa Maria, e estimular o acesso livre e democrático à literatura e à discussão literária. A Festa não tem viés comercial e conta com patrocínios de editais públicos e com a colaboração de autores, professores e alunos, participantes do projeto. Teve sua primeira edição em 2018, e, em

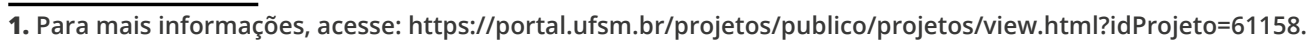


Festa literária de Santa Maria em casa: atuação no contexto de pandemia Camila Steinhorst • Aylon de Oliveira Dutra, et al...

2020, em função da pandemia de coronavírus, modificou-se para uma edição virtual, através de uma programação variada transmitida pelo YouTube, pelas redes sociais e pelo site do evento.

A FLISM EM CASA contou com painéis de discussão literária, de caráter temático ou relacionados a obras de autores convidados, como Cristóvão Tezza, Eliana Alves Cruz e Luiz Antonio de Assis Brasil, ou homenageados, como Clarice Lispector. Além disso, promoveu novas ações a fim de envolver o público com o evento: Drops Literários, em que os organizadores do evento e alguns convidados liam trechos de obras literárias; e $O$ que estou lendo?, em que escritores e professores da região contavam suas experiências literárias durante a quarentena. Essa última edição recebeu o apoio financeiro do edital de incentivo a ações de extensão relativas ao enfrentamento da pandemia de COVID-19, promovido pela Pró-Reitoria de Extensão da UFSM. Esse apoio possibilitou, por exemplo, a criação do site para veicular o conteúdo da terceira edição e as memórias das duas anteriores.
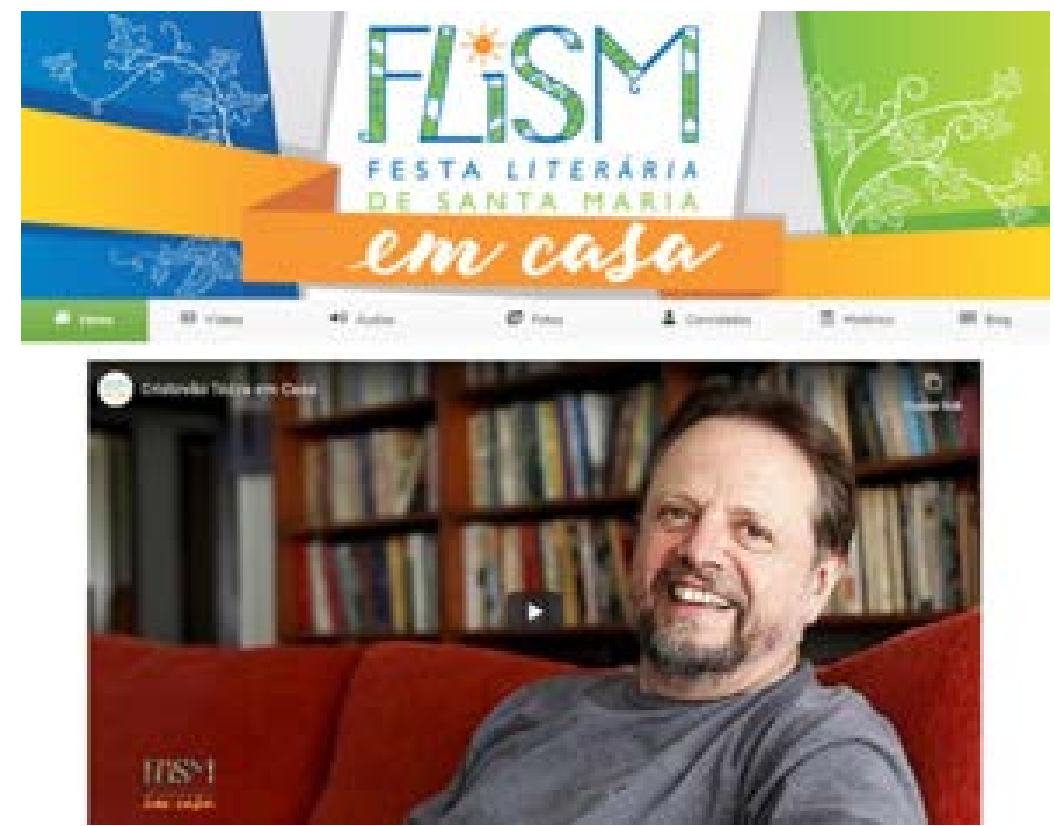

Figura 1: Print do Site da FLISM

Fonte: www.flism.com.br 
Festa literária de Santa Maria em casa: atuação no contexto de pandemia Camila Steinhorst • Aylon de Oliveira Dutra, et al...

No Brasil, as instituições de ensino superior (IES) possuem três pilares básicos: Ensino, Pesquisa e Extensão. Segundo Sandra de Deus (2020, p. 18), "os princípios da indissociabilidade deste tripé, bem como os princípios da autonomia universitária, estão estabelecidos na Constituição Brasileira de 1988". De modo geral, cabe à extensão desenvolver projetos, programas e ações extensionistas em interação com a comunidade geral, ou seja, com o público não universitário, a fim de difundir benefícios conquistados no âmbito da universidade.

Com relação à importância da Extensão, Deus (2020, p. 23) comenta que

8

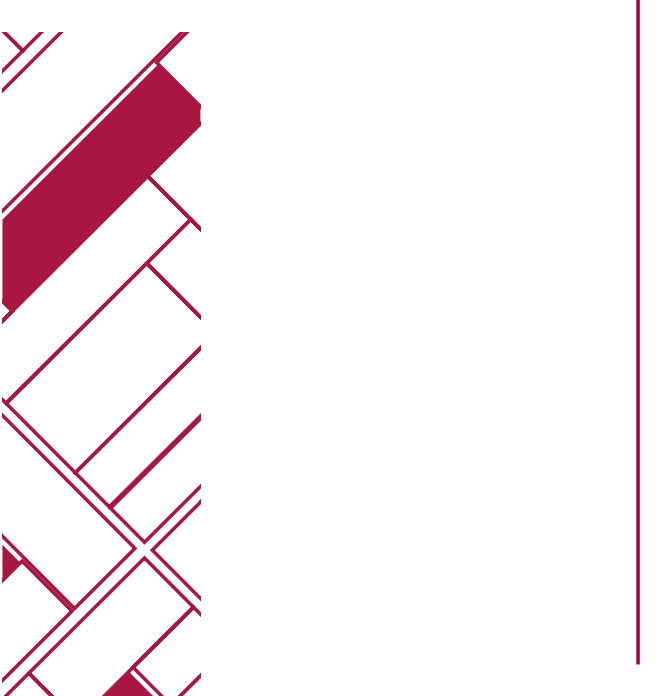

\begin{abstract}
A Extensão é o lugar da "alteridade" por excelência - é onde a universidade realiza o reconhecimento da diversidade tanto sociocultural quanto étnico-racial e permite não apenas a construção, como também o estabelecimento dos compromissos necessários à leitura do mundo. Ao atuar nas dimensões estéticas e culturais, a Extensão Universitária tenciona o Ensino e atualiza a Pesquisa. Este movimento nos convoca não só a pensar o lugar da Extensão na formação cidadã dos envolvidos, como também a reconhecer o seu papel real e objetivo na estrutura da universidade, no cumprimento daquela que pode ser uma de suas tarefas mais generosas e instigantes: a de ser o local de formação, contribuição e promoção de propostas para melhoria da vida.
\end{abstract}

Considerando as demandas sociais vigentes com relação à leitura, à pandemia do novo coronavírus e à relevância de ações de extensão e de cultura, objetivamos refletir, neste artigo, sobre o potencial que as festas literárias podem assumir, analisando especificamente a FLISM, com base na abordagem específica do seu 
Festa literária de Santa Maria em casa: atuação no contexto de pandemia Camila Steinhorst • Aylon de Oliveira Dutra, et al...

contexto de produção e recepção. Para isso, partimos de relatos de participantes da última edição online para tecer considerações acerca dos benefícios do evento para o público envolvido.

\section{Percurso investigativo}

Neste trabalho, realizamos uma pesquisa descritiva, adotando a abordagem quantitativa e qualitativa. Para a análise quantitativa, utilizamos dados presentes no relatório de prestação de contas da segunda edição do evento (2019) e os disponibilizados pelas plataformas digitais da terceira edição (2020), realizada de forma remota devido ao contexto de pandemia de COVID-19. Para a análise qualitativa, utilizamos como instrumento investigativo um formulário online para analisarmos a recepção dos participantes. Além disso, construímos reflexões teóricas a partir de Candido (2004), Morin (2007), Zilberman (2013), Cosson (2016) e Gallian (2017).

O universo de análise deste trabalho compreende os participantes da última edição (FLISM em casa) - professores na Educação Básica e Superior, graduandos em Letras e em outras áreas do conhecimento, pós-graduandos em Letras, servidores de instituições públicas, estudantes de Ensino Médio, escritores e aposentados, de diversos municípios e estados do Brasil. Partimos desses relatos para tecer considerações acerca dos benefícios do evento com relação à mediação cultural e de leitura.

Os dados foram gerados a partir de um formulário online, aplicado nas primeiras transmissões online da FLISM EM CASA, composto por quatro solicitações: i) profissão, ii) se fazia ou não parte do contexto universitário, iii) se o evento atendia a expectativas e iv) comentários. Ao todo, obtivemos 161 respostas no formulário, sendo que cada pergunta recebeu um determinado número 
Festa literária de Santa Maria em casa: atuação no contexto de pandemia Camila Steinhorst • Aylon de Oliveira Dutra, et al...

de respostas. Em suma, selecionamos 13 exemplos significativos referentes a duas solicitações do formulário: De modo geral, o evento está atendendo a suas expectativas e Comentários, sugestões e/ou perguntas sobre o evento para pensarmos a relevância da FLISM para os participantes. Convém ressaltar que selecionamos os relatos que possuíam mais do que uma informação assertiva do tipo "sim"; também que os participantes serão identificados como R1, R2...R13, a fim de preservarmos o anonimato.

\section{A Festa Literária de Santa Maria: objetivos e ações}

Com três edições já realizadas, duas sediadas na Cooperativa de Estudantes de Santa Maria (Cesma) e uma online, com transmissão via YouTube, devido à pandemia de COVID-19, a FLISM, apesar de modesta, se comparada a outras grandes festas literárias nacionais, apresenta uma programação variada, abrangendo diferentes gêneros (poema, crônica, romance, quadrinhos, narrativa transmídia etc), autores (clássicos, contemporâneos, nacionais, estrangeiros, gaúchos e santa-marienses) e mesas temáticas (literatura de autoria feminina, literatura fantástica, literatura e pandemia, literatura e distopia, sobrevida da personagem etc).

Segundo Oliveira (2019), um dos objetivos da programação é buscar a aliança entre gêneros mais conhecidos dos leitores jovens, como as histórias em quadrinhos e a literatura fantástica, e a discussão de clássicos do cânone ocidental, como Machado de Assis e Oscar Wilde, buscando combater a dicotomia erudito e popular. Dessa maneira, os painéis objetivam apresentar a literatura para o público geral, com uma linguagem acessível, em tom de conversa descontraída, entre o mediador, o(s) especialista(s) e/ou 
Festa literária de Santa Maria em casa: atuação no contexto de pandemia Camila Steinhorst • Aylon de Oliveira Dutra, et al...

o(s) escritor(es), sem o predomínio de uma linguagem acadêmica. Essa característica não torna os debates insipientes ou rasos, ao contrário, o que a FLISM busca é uma abordagem qualitativa, que aproxime os mais variados leitores de literatura.

A FLISM também conta com a presença de escritores, tanto autores renomados internacionalmente e nacionalmente, quanto autores regionais e locais, proporcionando o encontro com o público. Nesse sentido, é bastante pertinente o propósito da festa de, não só dar a oportunidade ao público santa-mariense de conhecer autores já consagrados da literatura brasileira, mas também divulgar e promover autores com produção ainda pouco conhecida, como foi o caso de uma das autoras convidadas para a FLISM 2020, Eliana Alves Cruz. Nas duas primeiras edições, escritores como Luiz Ruffato, Ignácio de Loyola Brandão, Letícia Wierzchowski e Leonel Caldela participaram de sessões especiais para autógrafos, tornando ainda mais significativa essa troca entre leitor e escritor. Além disso, na edição de 2019, jovens estudantes de entre 11 e 15 anos também publicaram sua obra, produto final de oficinas de haicai com a mediação do escritor Márcio Grings, acontecimento que possibilitou aos alunos assumirem o papel de autores.

Em busca de estreitar a relação da literatura com o mundo do leitor e de despertar o interesse dele pelo conhecimento literário, os objetos de discussão na FLISM giram em torno da formação e do repertório de leitura dos escritores, da possível relação entre as obras e contexto de produção e recepção (a recepção de determinada obra na sociedade, ao percurso do autor, as dificuldades em publicar um livro no mercado editorial, as projeções éticas e críticas da ficção), de temáticas (identidade feminina, racismo, desigualdade social etc) e de questões formais (narrador, personagem, estilo etc). Os painéis podem ter uma grande importância para a 
Festa literária de Santa Maria em casa: atuação no contexto de pandemia Camila Steinhorst • Aylon de Oliveira Dutra, et al...

formação de leitores, porque abrangem questões diversas de uma obra e/ou da vida de um escritor, favorecendo a ampliação dos conhecimentos dos participantes, a motivação para que se interessem por outras obras, bem como o aprimoramento de competências socioemocionais a partir da leitura literária. Essa abordagem pode favorecer a significação de uma leitura e até mesmo incitar o participante a reler determinada obra.

Para transcender os muros acadêmicos e melhorar o acesso da comunidade em geral à discussão literária, as primeiras edições do evento ocorreram presencialmente no centro da cidade. Esse deslocamento do espaço institucional é importante, porque rompe certo estereótipo que associa o conhecimento literário a pessoas tidas como "cultas", "superiores", o que afasta um público mais jovem e até mesmo um público adulto que não se sente à vontade com a formalidade da universidade.

Conforme o relatório da segunda edição da FLISM (2019), o evento contou com a participação de mais de 800 ouvintes, incluindo professores e alunos de escolas particulares e públicas, de diferentes cursos da UFSM e de outras instituições de Ensino Superior da cidade, assim como leitores em geral (OLIVEIRA, 2019). A terceira edição (2020), por sua vez, abrangeu um público mais diversificado devido às transmissões online via YouTube ${ }^{2}$ e site ${ }^{3}$. Conforme dados oficiais do YouTube, o canal do evento teve até o momento ${ }^{4} 5.200$ mil visualizações, totalizando 814,7h.

A faixa etária dos participantes é outra variável importante para a formação de leitores, pois percebemos que a grande maioria do público são pessoas entre 18 e 34 anos, conforme veremos a seguir na figura 1, ou seja, o público jovem foi o que mais acompanhou a programação.

\footnotetext{
2. Acesse o canal no YouTube em: https://www.youtube.com/channel/UCAdQVtO2TNdgVXdkkURzecw

3. Acesse o site do evento em: https://flism.com.br/

4. A data se refere ao momento de escrita deste artigo, julho de 2020.
} 
Festa literária de Santa Maria em casa: atuação no contexto de pandemia Camila Steinhorst • Aylon de Oliveira Dutra, et al...

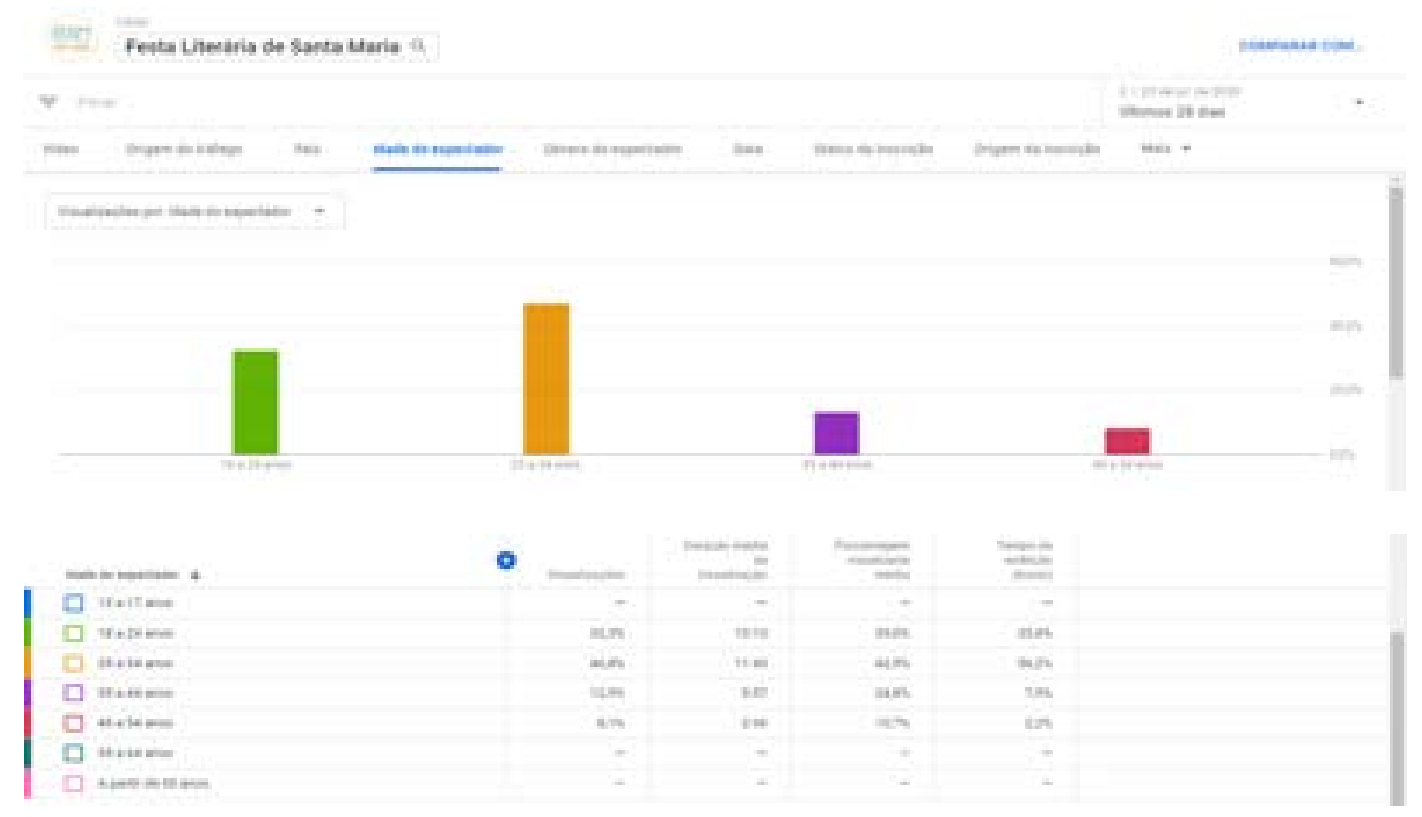

Figura 2: Dados referentes à faixa etária dos espectadores Fonte: YouTube (2020)

Entre o público total, estão estudantes de graduação e pós-graduação, professores da rede básica, professores da rede superior, escritores e servidores de universidades, assim como pessoas da comunidade em geral. Destacamos que, por meio da transmissão online, diversos estudantes de outras universidades, fora do estado do Rio Grande do Sul, tiveram a oportunidade de participar da FLISM. Assim, o evento obteve uma participação expressiva de pessoas de outras instituições e de outros estados brasileiros, o que expandiu sua contribuição para a formação de leitores, a troca de experiências culturais e a própria visibilidade do evento.

O formato online dessa edição favorece a ideia de que as novas tecnologias não atrapalham a difusão da leitura, mas sim promovem a formação de leitores. Concordamos com Zilberman (2013, p. 188), quando ela defende que a leitura não sofre ameaça na realidade virtual, mas se fortalece, porque conta com mais um mecanismo de difusão. Assim, "quanto mais se expandir o uso da 
Festa literária de Santa Maria em casa: atuação no contexto de pandemia Camila Steinhorst • Aylon de Oliveira Dutra, et al...

escrita por intermédio do meio digital, tanto mais a leitura será chamada a contribuir para a consolidação do instrumento, a competência de seus usuários e o aumento de seu público".

Tendo em vista as dificuldades de adaptação que o Ensino e a Extensão enfrentaram e enfrentam em meio ao isolamento social, provocado pela pandemia de COVID-19, a realização de uma edição online contribuiu para a continuidade da FLISM como projeto de extensão. Assim, a FLISM em casa buscou preservar os objetivos originais da festa e combater os impactos negativos da pandemia sob a seguinte justificativa:

\begin{abstract}
Neste momento, a leitura e a reflexão que ela promove tornam-se indispensáveis para viver, quando não para sobreviver. Na situação de crise e desespero por que passamos, marcada por uma ruptura na ordem rotineira da vida, precisamos manter vivo o fluxo de conhecimento e ação entre as diferentes interfaces que configuram o público para transpor o vazio entre o individual e o comum; ao mesmo tempo em que contribuímos para a construção de novos valores, vínculos e diversidades, ao redesenhar tecnologias de escuta e de ação. A arte compartilhada ao redor do mundo através das varandas e das janelas das casas é um forte indício dessa necessidade. A artesania literária vive e sobrevive do seu diálogo intensivo com a sociedade (PORTAL DE PROJETOS UFSM, 2020).
\end{abstract}

Para promover a leitura e a reflexão sobre o contexto de pandemia, o evento contou com as seguintes temáticas, relacionadas à literatura: pandemias, isolamento, distopia, biopolítica e necropolítica. As sessões de literatura e pandemias, por exemplo, envolveram a discussão de obras como Decameron, de Giovanni 
Festa literária de Santa Maria em casa: atuação no contexto de pandemia Camila Steinhorst • Aylon de Oliveira Dutra, et al...

Boccaccio, abordando o modo como as personagens contornaram a Peste Bubônica, que atingiu a Itália no século XIV. Houve ainda sessões com a participação de autores renomados, como Cristovão Tezza e painéis comemorativos, a exemplo da Homenagem a Clarice Lispector com a Profa. Dra. Nádia Battella Gotlib. Todos os painéis foram acompanhados e comentados pelo público em chat síncrono, durante a transmissão do evento, e estão disponíveis para acesso no site do evento (www.flism.com.br), bem como no canal do YouTube.

Além dos painéis, o evento desenvolveu outras iniciativas: precisamente, a promoção de duas coleções de vídeos, intituladas Drops Literários e O Que Estou Lendo, material audiovisual, com curta extensão, a fim de atingir um maior público e promover engajamento com as redes sociais da FLISM, antes mesmo das datas oficiais de sua realização (entre os dias 08 e 24 de julho). Os Drops procuraram estimular a participação e a reflexão sobre temas universais (morte, amor, distopia) a partir da leitura literária. Participantes do projeto, organizadores do evento, professores e escritores convidados produziram áudios lendo obras de diversos autores, para divulgá-los nas redes sociais (Facebook, Twitter e Instagram) do evento. Essa ação construiu um mosaico de vozes, que foram compartilhadas no mural de variados perfis, atingindo e afetando mais pessoas. A promoção d'O que estou lendo seguiu o mesmo movimento, porém com um enfoque diferente. Nessa proposta, os convidados (professores, editores e escritores) teciam comentários sobre sua rotina de leitura na pandemia e indicações sobre alguma obra que julgavam relevante, pouco conhecida ou pouco valorizada. Acreditamos que a disponibilização desse material online colabora com a formação continuada de professores e alunos e incentiva a leitura e a reflexão. 
Festa literária de Santa Maria em casa: atuação no contexto de pandemia Camila Steinhorst • Aylon de Oliveira Dutra, et al...

\section{Resultados: a resposta do público}

Neste tópico, refletimos sobre a importância da FLISM como mediadora cultural. Para isso, adotamos alguns comentários de participantes da terceira edição em um formulário que disponibilizamos durante o evento, relacionando-os com os conceitos de humanização, letramento literário e inter e transdisciplinaridade, conforme respectivamente Candido (2004), Cosson (2016) e Morin (2007). Em suma, selecionamos 13 exemplos significativos referentes a duas solicitações do formulário: De modo geral, o evento está atendendo a suas expectativas? e Comentários, sugestões elou perguntas sobre o evento para pensarmos a relevância da FLISM para os participantes. É importante ressaltar que, apesar da seleção restrita, todos os comentários sugeriram uma avaliação positiva do evento.

Quando perguntados De modo geral, o evento está atendendo a suas expectativas?, algumas respostas se sobressaíram, por oferecerem maior detalhamento (não apenas um "sim"), conforme veremos a seguir. Mantivemos a forma como os participantes escreveram os comentários, não alterando qualquer inadequação gramatical.

No primeiro momento, ressaltamos os comentários de professores com relação ao evento. Dessa forma, percebemos que a FLISM atua como referência aos docentes de Escolas Básicas: (R1) “Muito, pois em tempos de pandemia, nada melhor do que entrelaçar a atualidade com a literatura. Fascinante! Ótimo 'gancho' para trabalhar com meus alunos". A partir desse comentário, notamos que o evento atua como mediador entre literatura e professor, pois disponibiliza material para se pensar a confluência entre realidade e ficção, sugerindo possibilidades de trabalho com a literatura em sala de aula. 
Festa literária de Santa Maria em casa: atuação no contexto de pandemia Camila Steinhorst • Aylon de Oliveira Dutra, et al...

Outro comentário também sugere que o evento presta apoio ao trabalho docente: (R2) "Sim! Meu objetivo é aprender ainda mais sobre obras literárias para poder trabalhá-las com meus alunos. Ao mesmo tempo que fico motivada a ler as obras que ainda não conheço". Esse segundo relato revela que, além de atuar como uma referência, a FLISM desperta a motivação de professores a lerem outras obras, até porque um dos objetivos principais da FLISM é divulgar autores e obras pouco conhecidas do público. Nesse sentido, o evento também favorece o letramento literário de profissionais da área, expandindo seu repertório de leitura.

Paulino e Cosson (2009, p. 67) afirmam que letramento literário é o "processo de apropriação da literatura enquanto construção literária de sentidos". Ao refletirmos sobre esse conceito, percebemos que tal apropriação não é propiciada apenas pela escola, mas também em ambientes não formais, como festas literárias, feiras do livro, oficinas, entre outros. O autor comenta que o processo de letramento é contínuo e envolve desde as canções de ninar que ouvimos quando crianças até novelas que assistimos quando adultos, ou seja, é um processo que se expande por toda nossa vida.

No segundo momento, percebemos que alunos de letras também se beneficiam do evento como fonte de estudo, pesquisa e repertório: (R3) "Sim, por ser uma estudante de letras, tenho adorado ouvir especialistas discorrendo sobre obras clássicas"; (R4) “creio que sim, pois estou aproveitando esse cenário apocalíptico pra aperfeiçoar meus conhecimentos literários..."; (R5) "Sim. Está sendo um evento muito interessante e importante para se manter um vínculo com a faculdade e seus devidos assuntos". Notamos, a partir das expressões linguísticas "tenho adorado" e "está sendo um evento muito interessante importante", que a FLISM desperta motivação e prazer aos participantes da área de Letras. 
Festa literária de Santa Maria em casa: atuação no contexto de pandemia Camila Steinhorst - Aylon de Oliveira Dutra, et al...

Participantes já formados, que atuam em outras áreas do conhecimento, também sugerem a importância do evento para o conhecimento inter e transdisciplinar: (R6) "Sim. Sou formado em Letras - Língua Portuguesa. já participei de outras edições. Hoje curso Ciências Sociais, uma vez que relações entre literatura contemporânea, sociologia, antropologia e filosofia me interessam". Segundo Morin (2007, p. 45), cada vez mais as disciplinas se fecham e não se comunicam umas com as outras, o que torna a abordagem dos fenômenos fragmentados para o ensino e a aprendizagem. Em contrapartida, ele argumenta que "a constituição de um objeto interdisciplinar, polidisciplinar e transdisciplinar permite criar a troca, a cooperação e a policompetência", fazendo progredir os saberes a partir da complexificação das disciplinas, o que permite "articular domínios disciplinares num sistema teórico comum" (MORIN, 2007, p. 47). Nessa perspectiva, a FLISM cumpre um papel relevante para as ciências humanas, pois viabiliza diálogos e interrelações com outras disciplinas.

Além do diálogo com outras áreas, notamos relatos sobre a expansão da visão do mundo de participantes: (R7) “Está abrindo minha mente para certas questões em que eu ainda não tinha um bom conhecimento", favorecendo a criticidade e a diversidade de pensamento: (R8) "Iniciei agora, na segunda semana, mas vejo a programação uma grande oportunidade de estudo e de pensar a Literatura de modo crítico e plural". Podemos relacionar essas respostas com a discussão de temas relevantes nas diferentes edições do evento, bem como com o potencial de humanização que a literatura possui.

Esse potencial, segundo Candido (2004), relaciona-se à função da literatura que, por sua vez, está ligada à complexidade da sua natureza. O autor distingue sua função em três níveis: 1) como construção de objetos autônomos; 2) como forma de expressão de 
Festa literária de Santa Maria em casa: atuação no contexto de pandemia Camila Steinhorst • Aylon de Oliveira Dutra, et al...

emoções e de visões do mundo e 3) como forma de conhecimento. Candido defende que a organização da literatura, ligada ao primeiro nível, é um fator que nos ajuda a organizar nossa mente e nossos sentimentos e, em seguida, a organizar nossa visão do mundo. Além disso, a mensagem contida nessa organização atua sobre nós, gerando impactos estéticos e aumentando nossa possibilidade de sentir algo através da materialidade literária. E, assim, o conjunto formado por conteúdo e forma também transmite conhecimento, principalmente no plano do subconsciente e do inconsciente, enriquecendo nossa percepção e nossa visão do mundo. É nesse sentido que a literatura humaniza, pois amplia nossa visão do mundo e aprimora nossa capacidade emocional e intelectual.

Em outro espaço do formulário, solicitamos que os participantes deixassem comentários e/ou sugestões sobre a FLISM. Percebemos respostas que mostram a importância do evento como mediador de experiências e conhecimentos: (R9) “Oportunidade única de poder ouvir e trocar com gigantes da literatura!"; (R10) "Agradeço a oportunidade de poder participar deste evento com tanta riqueza cultural e intelectual, pela contribuição tão importante dos arguentes para nossa literatura". Notamos ainda que os participantes reconhecem o evento como mediador cultural: (R11) "Muito bom ver que um evento cultural incrível como a FLISM não deixou de acontecer, mesmo com momento delicado que vivemos".

Relacionados ao contexto que vivemos, alguns comentários sugerem que o evento cumpre um papel importante com relação ao enfrentamento das emoções aflitivas causadas pela pandemia: (R12) "Muito interessante e acessível essa perspectiva nova de fazer encontros on-line [...] Creio que é muito importante nos aproximarmos da literatura num período difícil como esse a nossas saúdes mentais, nada melhor do que se conectar com a arte 
Festa literária de Santa Maria em casa: atuação no contexto de pandemia Camila Steinhorst • Aylon de Oliveira Dutra, et al...

para aliviar os dias". Nessa perspectiva, a literatura parece assumir uma função terapêutica estimulada pela forma como a FLISM foi programada tematicamente nesta edição extraordinária, isto é, o evento atuou como agente humanizador, quando fortaleceu a reflexão sobre a temática da pandemia e aproximou os participantes, quando promoveu a discussão em grupo e o compartilhamento de pontos de vista sobre determinado tema, texto ou fato.

Com relação a isso, Gallian (2017) demonstra, em seu livro A literatura como remédio, que a leitura em grupo pode contribuir para o bem-estar dos participantes, aliviando emoções aflitivas e aumentando o senso de pertencimento. Segundo o pesquisador, a nossa necessidade de comunicação faz com que nos estimulemos a trocar com o outro, compartilhando afetos, reflexões, questionamentos e descobertas. Nessa perspectiva, vê a leitura literária como terapêutica, tendo em vista o potencial transformador e humanizador da própria literatura.

Por fim, diagnosticamos que o evento também atua para preservar e democratizar um patrimônio cultural e universal: (R13) "Parabéns pela excelente iniciativa! A literatura é imortal e espaços como esses são paraísos ao serviço da biblioteca universal!". A partir desse comentário, ressaltamos a importância da FLISM como mediadora da discussão de obras clássicas e contemporâneas, propiciando a reflexão sobre diversas temáticas, alimentando uma comunidade leitora que compartilha saberes e, acima de tudo, apropria-se desse conhecimento que, apesar de universal, ainda não é de todos.

Enfim, ressaltamos a noção de que a literatura é um direito humano (CANDIDO, 2004), assim como a alimentação, a moradia e o lazer, porque também é uma necessidade humana. Acreditando nisso, a FLISM procura transformar a possibilidade teórica e legal do direito à literatura em realidade, empenhando-se em democra- 
Festa literária de Santa Maria em casa: atuação no contexto de pandemia Camila Steinhorst • Aylon de Oliveira Dutra, et al...

tizar esse bem cultural ao mesmo tempo em que se esforça para perpetuá-lo, tornando a prática literária mais significativa a partir de debates contextualizados e qualificados.

\section{Considerações finais}

Neste artigo, objetivamos refletir sobre o potencial das festas literárias para a mediação cultural e para a formação de leitores, especificamente a Festa Literária de Santa Maria (FLISM), projeto de extensão da UFSM. Para isso, realizamos algumas reflexões com base em dados qualitativos e quantitativos colhidos nas três edições do evento.

Como resultados da análise dos comentários dos participantes da última edição online, percebemos que o evento: i) atua como mediador entre literatura e professor, pois disponibiliza material para se pensar a confluência entre realidade e ficção, sugerindo possibilidades de trabalho com a literatura em sala de aula; ii) favorece o letramento literário de profissionais docentes da Educação Básica, contribuindo para a expansão do seu repertório de leitura; iii) desperta a motivação e o prazer de alunos de letras, os quais também se beneficiam do evento como fonte de estudo e pesquisa; iv) dialoga com outras áreas do conhecimento; v) estimula a expansão da visão do mundo de participantes, valorizando a diversidade e incentivando a criticidade; vi) auxilia o enfrentamento de emoções aflitivas; vii) preserva e democratiza um patrimônio cultural que é a literatura.

De forma geral, a realização de uma edição online possibilitou a participação de autores de outros estados, bem como a de professores e estudantes de diversas instituições no evento. Em termos financeiros, facilitou o corte de custos com transporte, 
Festa literária de Santa Maria em casa: atuação no contexto de pandemia Camila Steinhorst • Aylon de Oliveira Dutra, et al...

hospedagens e com infraestrutura (aluguel, som etc). Ao mesmo tempo, exigiu conhecimentos específicos dos organizadores, entre eles um grupo variado de discentes da Pós-graduação e da Graduação em Letras da UFSM, sobre novas tecnologias e comunicação em rede. Assim, evidenciamos que a última edição promoveu também o aprimoramento do letramento digital de seus organizadores. Como desafios, destacamos que um evento online exige muito trabalho com divulgação (produção de artes, postagens frequentes etc) para alcançar engajamento, tendo em vista a gama de eventos disponíveis nesse período.

Para finalizarmos nossas reflexões, perguntamo-nos: para que serve uma festa literária? Atrevemo-nos a afirmar que as festas literárias, a exemplo da FLISM, existem e resistem para demarcar o lugar da literatura em espaços públicos e democráticos nas cidades brasileiras. Através de seu grande potencial para a mediação cultural e para a formação de leitores, o evento cumpre a função de democratizar o acesso à cultura, de forma gratuita e aberta a todos os públicos, promovendo uma programação diversa e necessária para o letramento literário dos participantes, que engloba textos clássicos e contemporâneos, autores conhecidos internacional e regionalmente, e possibilita a descoberta de novos autores, debates e reflexões sobre temáticas variadas. No contexto pandêmico de 2020, esse potencial de resistência, de certo modo, aumentou quando a FLISM conseguiu ampliar o público participante e garantir que o material da Festa esteja disponível, em rede, a todos os interessados.

Certamente não devemos pensar que, com isso, o evento resolva os problemas locais relacionados ao acesso à cultura, quanto mais se pensarmos na realidade nacional. Devemos expandir os resultados que conseguimos conquistar e buscar novas maneiras de contornar dificuldades. Como desafios para a ampliação des- 
Festa literária de Santa Maria em casa: atuação no contexto de pandemia Camila Steinhorst • Aylon de Oliveira Dutra, et al...

ses resultados, ressaltamos a importância de intensificar o diálogo com as escolas a fim de desenvolvermos uma parceria mais sólida que promova a participação dos alunos e, consequentemente, um maior envolvimento de toda a comunidade. Além disso, outro desafio é dar sequência a programação anual do evento.

Dessa forma, a FLISM continuará a construir junto de seus participantes sentidos para textos literários e para a própria literatura em suas vidas. Acreditamos que a permanência de festas literárias e outras ações extensionistas voltadas à cultura podem ser mais um movimento de encontro entre leitor, autor e obra, que possibilite a democratização do acesso à arte em um país tão desigual. Assim, estaremos atuando para garantirmos direitos e potencializarmos a significação da leitura literária por meio de espaços de compartilhamento.

\section{3}

\section{Referências}

BRASIL. Lei n. 13.696, de 12 de julho de 2018. Institui a Política Nacional de Leitura e Escrita. Disponível em: htTp://www.planalto.gov.br/ccivIL_03/_ATO2015-2018/2018/LEI/L13696.HTM. ACESSO EM: 20 SET. 2020.

CANDidO, A. O direito À literatura. IN: Vários escritos. 3. ed. São Paulo: DuAs Cidades, 2004.

COSSON, R. Letramento literário: teoria e prática. São Paulo: Contexto, 2016.

COSSON, R. Círculos de leitura e letramento literário. São Paulo: ConTEXTO, 2019.

DEUS, S. de. Extensão Universitária: trajetórias e desafios. Santa Maria, RS: Ed. PRE-UFSM, 2020. 
Festa literária de Santa Maria em casa: atuação no contexto de pandemia Camila Steinhorst • Aylon de Oliveira Dutra, et al...

FESTA literÁRIA DE SANTA MARIA. Cristovão Tezza em CASA. 8 JUl. 2020. Página Inicial. Disponível em: WWW. Flism.COM.br. ACESSO EM: 10 nov. 2020.

GALLIAN, D. A literatura como remédio: os Clássicos e a saúde da alma. São Paulo: Editora Martin Claret, 2017.

inStituto PRÓ-LiVRO. Retratos da Leitura no Brasil. São Paulo: INSTITUTO PRÓ-LIVRO, 2016.

MORIN, E. Educação e complexidAde: os SETE SAberes E outros ensaios. AlmeidA, M. da C. de.; CARVAlHO, E. de A. (Orgs.). 4. ed. São Paulo: CORTEZ, 2007.

OLIVEIRA, R. T. DE. ReLATÓRIO FINAL DE EXECução dA SEgUNDA EDIÇÃo dA Festa Literária de Santa Maria. Prefeitura de Santa Maria, 2019, 107p.

\section{4}

PAULINO, G.; COSSON, R. LETRAMENTO LITERÁRIO: PARA VIVER A LITERATURA DENTRO E FORA DA ESCOLA. In: ZILBERMAN, R.; RÖSING, T. M. K. (ORGs.). Escola e leitura: velha crise; novas alternativas. São Paulo: Global, 2009. PETIT, M. Leituras: do espaço íntimo ao espaço público. São Paulo: EditoRA 34, 2013.

PORTAL DE PROJETOS DA UFSM. FLISM EM CASA. DISPONÍVEL EM: HTTPS://PORTAL.UFSM.BR/PROJETOS/PUBLICO/PROJETOS/VIEW.HTML?IDPROJETO=66471. ACESSO EM: 10 NOV. 2020.

RÖSING, T. M. K. PromoçÃo da leitura e MOVIMENTAÇÕes CULtURAIS: AS Jornadas Literárias de Passo Fundo. IN: ZILBERMAN, R; RÖSING, T. M. K. (Orgs.). Escola e leitura - Velha crise, novas alternativas. São Paulo: GLOBAL, 2009. 
Festa literária de Santa Maria em casa: atuação no contexto de pandemia Camila Steinhorst • Aylon de Oliveira Dutra, et al...

ZILBERMAN, R. A LEITURA NO MUNDO DIGITAL. IN: RETTENMAIER, M.;

RÖSING, T. M. K. (Orgs.). Questões de LeItURA No hiperTexto. UniversIdade de Passo Fundo, Editora UPF: 2013.

ZILBERMAN, R. A escola e a Leitura dA LITERATURA. IN: ZILBERMAN, R; RÖSING, T. M. K. (Orgs.). Escola E Leitura - VelHa CRISE, NOVAS ALternativas. São Paulo: Global, 2009.

\section{5}

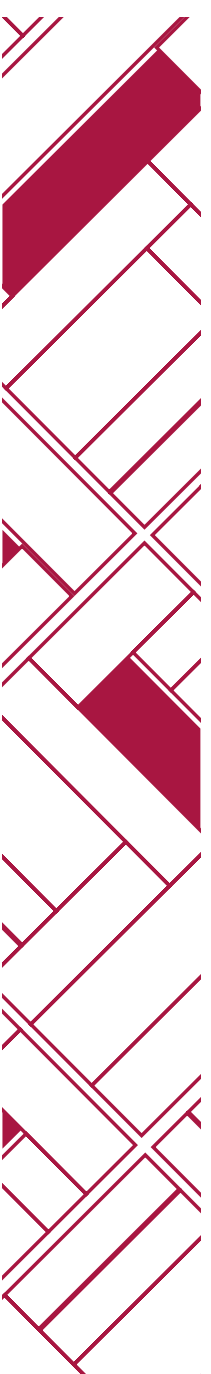

